\title{
Diagnostic algorithm for the confirmation of cases of measles and rubella in Mexico
}

Juan Francisco Román-Pedroza, ${ }^{1}$ Edith Cruz-Ramírez, ${ }^{1}$ Kathia Elia Landín-Martínez, ${ }^{1}$

Mónica Salas-García, ${ }^{1}$ Eduardo López-Ortiz, ${ }^{2}$ José Ernesto Ramírez-González, ${ }^{1}$ Irma López-Martínez年 and José Alberto Díaz-Quiñonez ${ }^{*}$

${ }^{1}$ Institute of Epidemiological Diagnosis and Reference "Dr. Manuel Martínez Báez"; Universidad Nacional Autónoma de México, Faculty of Medicine,

Postgraduate Studies Division. Mexico City, Mexico

\section{Abstract}

Due to the successful implementation of measles and rubella elimination strategies, Mexico announced the interruption of endemic transmission of measles in 1996 and that of rubella in 2008. After a verification process, the region of the Americas was declared free of rubella and congenital rubella syndrome in 2015 and of measles in 2016. In order to maintain the elimination status in Mexico, it is essential to continue laboratory surveillance within the framework of the Global Measles and Rubella Laboratory Network. The Institute of Epidemiological Diagnosis and Reference, through the National Network of Eublic Health Laboratories, guarantees timely and reliable results in view of the possible reintroduction of these and other emerging pathogens.

KEY WORDS: Diagnosis. Measles. Rubella. Mexico.

\section{Introduction}

Measles is a febrile exanthematous disease of mandatory surveillance in Mexico in accordance with Mexican legislation and regulations..$^{1,2}$ The disease is caused by the measles virus, which belongs to the Morbilivirus genus of the Paramixoviridae family. ${ }^{3}$ Measles receptors are expressed in many cell types, which explains its systemic symptomatic expression. Transmission occurs by propagation of droplets or direct contact with airborne nasopharyngeal secretions when an infected person coughs or sneezes. Up to $90 \%$ of susceptible people in direct contact with the secretions deriving from coughing and sneezing, or with the air or surfaces of the room where the patient is staying, can become infected in that period. ${ }^{4}$

Initial symptoms include fever, cough, nasal discharge and conjunctivitis, enanthem, maculopapular rash that starts in the head and spreads to the trunk and extremities. It can cause from mild symptoms to serious complications such as diarrhea, pneumonia, fever-associated seizures, corneal scars that result in blindness, encephalitis and death. Encephalitis,occurs in one of 100,000 cases and deaths in one to three in 1000; younger than five years and immunocompromised individuals are the most affected. Six to eight years after the condition, one in every 100,000 cases may develop subacute sclerosing pan-encephalitis as a complication due to the persistence of the virus in the cerebrospinal fluid. ${ }^{5}$

Incubation period is 10 to 12 days; the prodromes begin after exposure. The rash appears 14 days after the initial exposure, within a range of 7 to 21 dâys. Patients are contagious four days prior to the onset of exanthema and four days after its appearance. Immunocompromised patients are contagious
Correspondence:

*José Alberto Díaz-Quiñonez

E-mail: adiazq@unam.mx
Date of reception: 30-08-2019

Date of acceptance: 23-09-2019

DOI: 10.24875/GMM.M20000337
Gac Med Mex. 2019;155:492 495

Contents available at PubMed

www.gacetamedicademexico.com

0016-3813/C 2019 Academia Nacional de Medicina de México, A.C.. Published by Permanyer. This is an open access article under the CC BY-NG-ND license (http://creativecommons.org/licenses/by-nc-nd/4.0/). 
throughout the disease. ${ }^{5}$ The National Epidemiological Surveillance System defines a "probable case" of measles or rubella as any person of any age with fever and maculopapular rash and one or more of the following signs and symptoms: cough, coryza, conjunctivitis or adenomegalies (retroauricular, occipital or cervical); and a "confirmed case" of measles or rubella as any probable case where measles or rubella virus infection is demonstrated by laboratory techniques recognized by the Institute of Epidemiological Diagnosis and Reference "Dr. Manuel Martínez Báez" (InDRE), or a probable case that does not have a sample or laboratory result and that is epidemiologically associated with another laboratory-confirmed case. ${ }^{6}$

In Mexico, the Universal Vaccination Program has the triple viral vaccine as a specific protection measure for measles, rubella and mumps. The first dose is applied at 12 months of age. Although, in general, 90 to $95 \%$ of vaccinated individuals respond adequately, a second dose is applied at six years of age in order for those who had an immune response failure to adequately develop antibody protective levels. ${ }^{5}$

In September 2016, the Pan American Health Organization and the World Health Organization declared the region of the Americas the first in the world to be free of measles after 22 years of coordinated efforts within the member states. Measles became the fifth vaccination-preventable disease to be eliminated, after the eradication of smallpox, polio, rubella and congenital rubella syndrome. ${ }^{7}$ However, in 2017, an outbreak of measles occurred in Venezuela, which spread to Brazil and Colombia in 2018, ${ }^{8}$ deriving from migration to these countries. The same year, Argentina, Chile, Ecuador and Peru reported imported cases related to these countries. By the end of 2018, Brazil, Venezuela, the United States, Peru, Mexico, Colombia, Chile, Canada, Ecuador, Argentina, Guatemala, Antigua and Bermuda reported 16,514 confirmed cases. $^{9}$

By September 29, 2019, the Ministry of Health had a total of 16 confirmed cases reported on the federal government official website, ${ }^{10}$ four of them classified as imported, two under investigation and the rest associated with importation. ${ }^{11}$

\section{Laboratory diagnosis}

As the national reference laboratory certified by the Pan American Health Organization/World Health
Organization, the InDRE belongs to the World Network of Laboratories for the Diagnosis of Measles and Rubella since 1992. That same year, the National Network of Laboratories for Etiological Diagnosis of Febrile Exanthematous Disease started operating in Mexico. Currently, the National Network of Public Health Laboratories (RNLSP - Red Nacional de Daboratorios de Salud Pública) is integrated by 31 state public health laboratories and the Central Epidemiology Laboratory of the Mexican Institute of Social Security. In order to guarantee the quality of epidemiological information and appropriate adoption of control actions, the laboratory system is assessed using international standards.

The diagnostic algorithm and procedures issue by the InDRE, through the Laboratory of Febrile Exanthematous Disease, are established in the Guide for laboratory monitoring of febrile exanthematous diseases, ${ }^{3}$ approved by the National Committee for Epidemiological Surveillance and of mandatory observance for the RNLSP (Figure 1).

\section{Sample collection, handling and submission}

The samples for the diagnosis of measles, rubella and congenital rubella syndrome are serum and pharyngeal exudate. Both must be mandatorily and simultaneously taken, in order to carry out serological and molecular detection, for the confirmation of cases and genotype identification. The samples must comply with the operational definition of measles/rubella probable case or congenital rubella probable case and with the evolution days to be accepted in the processing laboratory.

\section{Sample collection and handling}

\section{Serum}

In the period from zero to 35 days of evolution from the date of exanthema onset, $5 \mathrm{~mL}$ of blood shguld be obtained by venous puncture, using a vacuum-extraction plastic tube, without anticoagulant, with or without separating gel. Once the sample is taken the tube should be labeled with the patient's name, type of sample and date, and stored at between 2 and $8^{\circ} \mathrm{C}$. It is necessary to separate the serum in a plastic tube with screw closure and identify it with patient and sample data. The volume of serum required is $1 \mathrm{~mL}$. In newborns, $1 \mathrm{~mL}$ of blood should be obtained by 


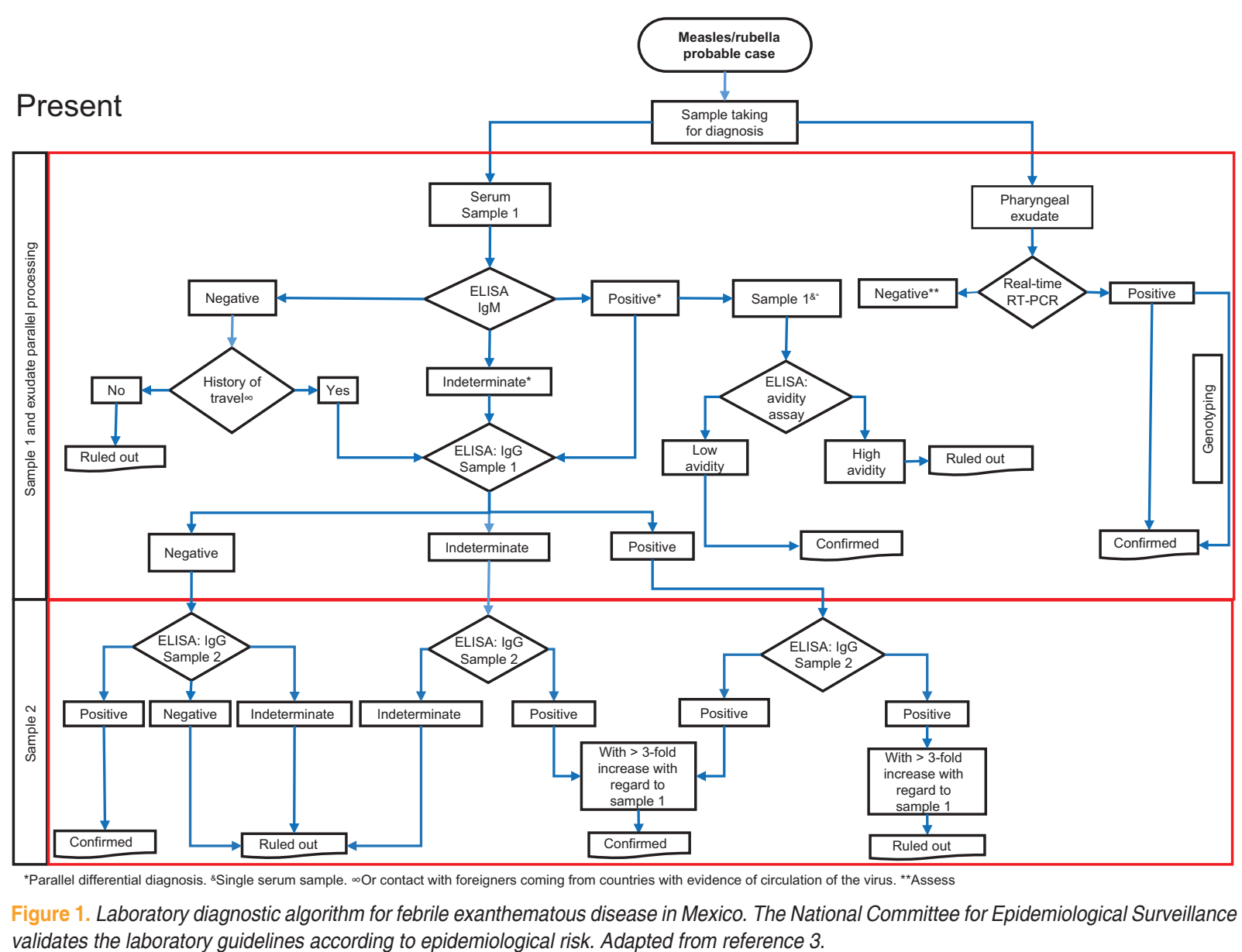
validates the laboratory guidelines according to epidemiological risk. Adapted from reference 3.

venous puncture, as the volume required in these cases is 100 to $200 \mu \mathrm{L}$. If a second sample is required for follow-up of the case, it should be obtained two weeks after the first one, within 30 days after the onset of exanthema.

\section{Pharyngeal exudate}

It should be obtained within the period of 0 to 5 days of evolution from the date of exanthema onset; the posterior wall of the pharynx is rubbed with a sterile dacron or rayon swab in order to detach epithelial cells. The swab is placed in $2 \mathrm{~mL}$ of sterile viral transport medium contained in a plastic tube with screw closure, labeled with the patient's name, date of sampling and type of sample.

\section{Sample submission and transportation}

All biological specimens should be transported in a triple packaging system, under refrigeration conditions
( 2 to $8^{\circ} \mathrm{C}$ ). The administrative conditions for submitting and receiving samples are described in detail in the Guidelines for laboratory surveillance of febrile exanthematous disease. ${ }^{3}$ This document describes the conditions whereby a sample could be rejected due to incidents in the process of taking, handling and submission.

\section{Diagnostic algorithm}

In the context of measles, rubella and congenital rubella syndrome elimination sustainability, laborầtory confirmation with an algorithm standardized for RNLSP is essential. ${ }^{12}$ Serum samples and pharyngeal exudate are processed in parallel, and must comply with the definition of probable case and days of evoIution. All sera are analyzed by enzyme-linked immunosorbent assay (ELISA) for measles/rubella, while all pharyngeal exudates are analyzed by reverse transcription coupled to polymerase chain reaction (RTPCR), in real time for both diagnoses (Figure 
The RNLSP carries out the serological diagnosis for identification of specific IgM and IgG antibodies, both for measles and for rubella, in addition to molecular diagnosis by real-time RT-PCR. The Institute of Epidemiological Diagnosis and Reference carries out the determination of IgG antibodies by avidity tests for measles and rubella (to differentiate primary and secondary immune responses), in addition to virological methods (viral isolation) and genetic characterization of the virus (genotyping), if the sample has an adequate quality.

In countries that have achieved elimination, such as Mexico, if a sample has an lgM-negative result for measles or rubella and the patient has a history of travels to countries with evidence of transmission of the virus, or contact with a person of foreign origin who comes from any of these countries, a second sample should be obtained to look for any increase in IgG antibodies. In samples with an IgM-positive result for measles or rubella, a second sample is also required to look for seroconversion and increase in IgG-specific antibody titers.

\section{Quality standards of the test}

Timeliness and quality in the taking and submission of samples, until the reception in the laboratory, are determinant to the reliability of the result. The laboratory guidelines describe the factors that affect the pre-analytical, analytical and post-analytical phase, the timing of the issuance of the result for the epidemiological surveillance system and for interested parties.

\section{Recommendations}

It is important for health personnel to know the case operational definitions for febrile exanthematous disease, which will facilitate a proper process of diagnostic confirmation by ensuring adequate collection, handling and submission of samples. The InDRE and the RNLSP have the technical and professional resources to establish a reliable and timely diagnosis and to support the actions of disease prevention and control.

\section{References}

1. Ley General de Salud. México: Secretaría de Salud; 2018

2. NOM-017-SSA2-2012, para la vigilancia epidemiológica. México: D̄iario Oficial de la Federación; 2013.

3. Lineamientos para la vigilancia por laboratorio de la enfermedadfebril exantemática. México: Secretaría de Salud/Instituto de Diagnóstico y Referencia Epidemiológicos "Dr. Manuel Martínez Báez"; 2018. 으

4. Centros para el Control y la Prevención de Enfermedades [sitio Web]. Transmisión del sarampión. EE. UU.: CDC; 2018.

5. Manual de vacunación. México: Secretaría de Salud/Centro Nacional para la Salud de la Infancia y la Adolescencia; 2017.

6. Manual de procedimientos estandarizados para la vigilancia epidemiológica de las enfermedades prevenibles por vacunación. México: Secretaría de Salud; 2018.

7. Linn L, Oliel S, Baldwin A. La región de las Américas es declaradalibre de sarampión. EE. UU.: Organización Panamericana de la Salud/Organización Mundial de la Salud; 2016.

8. Organización Panamericana de la Salud. Actualización epidemiøłégica sarampión. Organización Panamericana de la Salud/Organización-Mundial de la Salud; 2019

9. Sistema Nacional de Vigilancia Epidemiológica. Situación epidemiotógica de sarampión. México: Sistema Nacional de Vigilancia Epidemiolögica/ Comité Nacional de Vigilancia Epidemiológica; 2019.

10. Dirección General de Epidemiología. Sarampión, México: Casos Confirmados al 29/09/2019. México: Secretaría de Salud; 2019. Disponibłe en: https://www.gob.mx/cms/uploads/attachment/file/497412/Sarampion Mexico_Casos_Confirmados_2019.09.29_19hrs.pdf.

11. Situación epidemiológica de sarampión. México: Secretaría de Salud;:2019.

12. Orientaciones sobre las pruebas de sarampión y de la rubéola realizadas en la red de laboratorios de la Región de las Américas. EE. UU: Organización Panamericana de la Salud/Organización Mundial de la Salud;2018. 